\title{
DESIGN AND DEVELOPMENT OF A REFRIGERATOR DOOR GASKET TO PREVENT CONDENSATION
}

\author{
Mumin Gulmez ${ }^{1} \mathcal{E}$ Deniz Yilmaz ${ }^{2, *}$ \\ ${ }^{1}$ BSH Home Appliance Development Center, Istanbul, Turkey \\ ${ }^{2}$ Department of Mechanical Engineering, Istanbul Arel University, Istanbul, Turkey \\ *Address all correspondence to: Deniz Yilmaz, Mechanical Engineering Department, Istanbul Arel University, \\ 34537 Tepekent, Buyukcekmece, Istanbul, Turkey, E-mail: denizyilmaz@arel.edu.tr
}

Original Manuscript Submitted: 2/8/2020; Final Draft Received: 6/15/2020

\begin{abstract}
Refrigerators are one of the most frequently used household devices; therefore, they represent an interesting subject for investigations. One of these research topics is the condensation problem in the gasket region. Despite the use of heaters in the refrigerator door, condensation on the surface of the gasket may still occur. Thus, there is a need for an improved gasket structure to overcome the condensation on the surface of the gasket. The present study aims at development of a new gasket design to prevent condensation in its region of the refrigerator. Critical points, where condensation may occur on the gasket surface, were determined experimentally and the parameters of a new design were clarified by numerical analysis. Various air chambers were created in the gasket to change the temperature distribution on the surface for preventing condensation at some critical points. The effect of these air chambers' location on the temperature distribution in the gasket region was investigated and the temperature of the potential condensation zones was relatively increased.
\end{abstract}

KEY WORDS: refrigerator, condensation, gasket designing, refrigeration

\section{INTRODUCTION}

The inventions of the second industrial revolution have transformed people's lifestyles from a rural agricultural environment into an urban city environment. The refrigerator is one of these inventions that has affected peoples' lives. Today, domestic refrigerators are among the most used electrical appliances all over the world. When the literature is considered, it is seen that the researches on refrigerators are generally focused on reducing greenhouse gas emissions and energy efficiency (Bolaji and Huan, 2013; Boeng and Melo, 2014; Negrão and Hermes, 2011; Geppert and Stamminger, 2013; Bolaji, 2011). Energy saving requires conserving or improving efficiency. Thermal insulation and ensuring sealing performance are important parameters for energy saving in cooling devices. There are various ways to ensure refrigerator sealing; usually magnetic gaskets are preferred which are mounted in a peripheral inner portion of the door of the refrigerator. A gasket minimizes the amount of heat transfer between the outside and inside cabinets when the door is in the closed position. But it is known that the air infiltration rates were strongly dependent on the door seals conservation conditions (Afonso and Castro, 2010) and heat loss through magnetic gaskets can reach up to $30 \%$ of the total thermal loss of a domestic refrigerator (Gao et al., 2017; Belman-Flores et al., 2015). Compared to the thickness of the insulation on the refrigerator walls, the thickness of the gasket is relatively small and is a problematic area for heat leakage.

Apart from improving sealing, another important problem that needs to be solved on the gasket is condensation. The inner surface of the gasket remains in contact with the cabinet, while the outer surface faces the outer environment. The temperature differences between the outer and inner surfaces of the gasket may cause condensation. This is one of the main problems of refrigerators. At this point, manufacturers generally use hot loop in the front surface of the cabinet so as to minimize any such condensation due to any temperature differences between the refrigerator sections and the outside air. But it cannot completely eliminate condensation. At this point, changes in the design can be effective in solving the condensation problem. There is little or no information in the literature about refrigerator gasket design because it is generally a secret and/or patented by manufacturers (Belman-Flores 


\begin{tabular}{|c|c|c|c|}
\hline \multicolumn{4}{|c|}{ NOMENCLATURE } \\
\hline K & thermal diffusivity, $\mathrm{m}^{2} / \mathrm{s}$ & UA & overall thermal conductance, $\mathrm{W} / \mathrm{K}$ \\
\hline$p$ & pressure, $\mathrm{Pa}$ & $v$ & Y-component of velocity, $\mathrm{m} / \mathrm{s}$ \\
\hline$\dot{q}$ & heat transfer rate, $\mathrm{W}$ & \multirow{2}{*}{\multicolumn{2}{|c|}{ Greek Symbols }} \\
\hline$T_{\mathrm{A}}$ & ambient temperature, $\mathrm{K}$ & & \\
\hline$T_{\mathrm{c}}$ & average temperature inside & $\beta$ & coefficient of thermal expansion, $1 / \mathrm{K}$ \\
\hline & the cabinet, $\mathrm{K}$ & $v$ & kinematic viscosity, $\mathrm{m}^{2} / \mathrm{s}$ \\
\hline$u$ & $\mathrm{X}$-component of velocity, $\mathrm{m} / \mathrm{s}$ & $\rho$ & density, $\mathrm{kg} / \mathrm{m}^{3}$ \\
\hline
\end{tabular}

et al., 2015) or possibly due to the differences in cabinet and door designs, research efforts have been limited (Bansal et al., 2011). Also, the existing studies in the literature regarding refrigerator gaskets have generally focused on heat leaks. But, there was not any study concerning condensation on the surface of the gasket.

In this study, the condensation problem for a built-in refrigerators gasket is investigated and it was aimed at elimination of condensation on the surface of the gasket with a new design. Especially in built-in products, the fact that the devices are covered with furniture increases the condensation problem on the gasket surface and makes the solution of the problem difficult. The use of furniture creates a barrier between the refrigerator door and the room air so that the outer surface of the door is cooler than the room air. The refrigerator tested in the study is used with the same design all over the world, and it has been reported that condensation occurs in the gasket section especially in the hottest and most humid cities (Gulmez, 2019). This is the main starting point of this research. In this study, firstly experiments were carried out to determine the problem, and then a new gasket was designed with the data obtained from the experiments. In order to obtain a temperature distribution that will reduce condensation on the gasket surface, design changes have been made in the gasket sections, and the most suitable design parameters have been determined.

\section{EXPERIMENTAL STUDY}

The tests were carried out in the climate chambers located at the R\&D Cooling Center of BSH Bosch Household Appliances in Çerkezköy, Tekirdag, Turkey. In these chambers, many data such as temperature, relative humidity, air velocity, energy consumption, etc. can be recorded and monitored remotely at fixed time intervals. Laboratory and test conditions comply with the ISO/IEC 17025:2017 (2017) standards. T-type thermocouples were used as temperature sensors. The temperature measurement tolerance of these sensors is $\pm 0.01 \mathrm{~K}$, and its calibration is performed once a year by an accredited institution. Relative humidity measurements were carried out with SHT21 model humidity sensors. The measurement accuracy of these humidity sensors is $\pm 3 \%$. The household refrigerator used for this study contains a freezer and fridge sections. The refrigerator is of no-frost type. The external dimensions of the refrigerator are $0.904 \times 0.61 \mathrm{~m}$ (width $\times$ depth) and the height is $1.93 \mathrm{~m}$. The heights of the fridge and freezer sections are $1.25 \mathrm{~m}$ and $0.68 \mathrm{~m}$, respectively. The total internal volume of cabinet $(521 \mathrm{~L})$ is composed of the fridge section having a volume of $381 \mathrm{~L}$ and freezer section having a volume of $140 \mathrm{~L}$.

\subsection{Measurements for Estimation of Overall Refrigerator Thermal Conductance}

The most commonly used experimental method, reverse heat load method (RHLM), was used in the experiments (Sim and Ha, 2011; Liu et al., 2020). In this method energy input is equal to the heat leakage of the refrigerator to maintain a steady state. To increase the temperature of the refrigerator cabinet, electric resistance heaters are placed at the bottom of the sections, and the amount of power consumed by the heaters is recorded. Thermocouples were placed around the refrigerator to measure outside temperatures and along two walls at $15-\mathrm{cm}$ intervals to measure the temperature inside the refrigerator as shown in Fig. 1.

Before the tests, the refrigerator was kept in a test chamber conditioned to $16^{\circ} \mathrm{C}$ for $24 \mathrm{~h}$ until it reaches the same temperature as the test chamber. After the sections reached the same temperature with the test chamber, the 


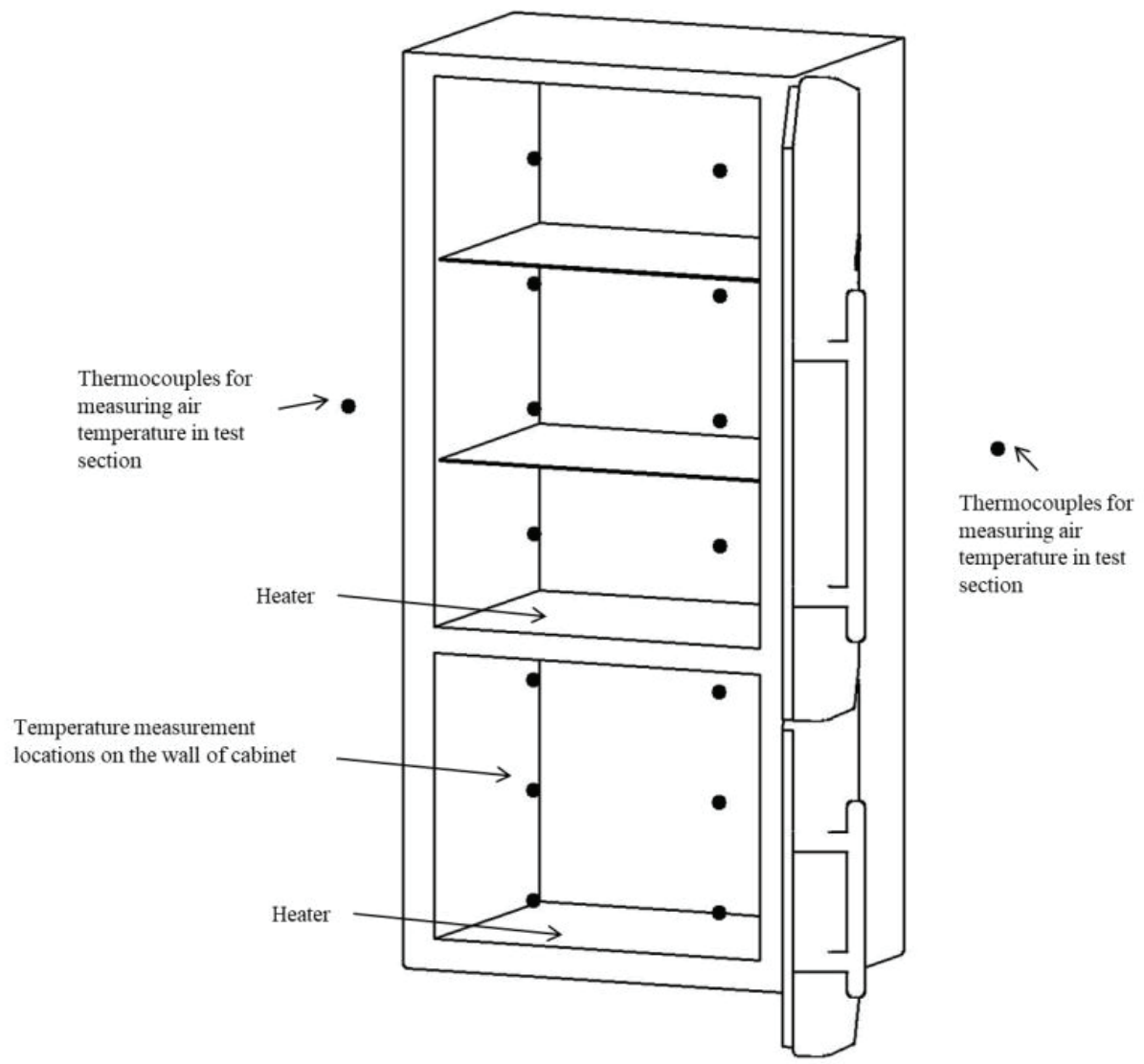

FIG. 1: Test setup to determine the overall thermal conductance

power applied to the heater was gradually increased, and the refrigerator sections stabilized at a constant temperature of $40^{\circ} \mathrm{C}$. After approximately $53 \mathrm{~h}$, the system has reached a steady state (see Fig. 2a). When the system reached a steady state, obtained data were used to determine the total heat loss rate and then overall thermal conductance (UA) was evaluated from Eq. (1) and calculated results are presented in Fig. $2 \mathrm{~b}$

$$
\mathrm{UA}=\frac{\dot{q}}{\left(T_{C}-T_{A}\right)} .
$$

\subsection{Measurements for Determination of Temperature Distribution in the Gasket Region}

In order to analyze the temperature distribution in the gasket region, it will be sufficient to examine the cross section of the region with a diameter of about $15 \mathrm{~cm}$, taking into account the results of preliminary researches. Since according to the BS EN 62552:2013 (2013) standard the kitchen conditions were defined as $25^{\circ} \mathrm{C}$ and the relative humidity was determined as $80 \%$ according to the most unfavorable conditions that will cause condensation.

The sectional view of the assembled gasket is shown in Fig. 3. As is seen in the figure, there is a magnet inside the gasket to ensure sealing. There is also a hot pipe installed around the freezer and fridge sections to prevent condensation. This hot pipe is located after the condenser in the cooling cycle and is heated by the hot refrigerant passing through it.

Thermocouples were placed at critical points to measure temperature in the gasket region (Fig. 4). The measurement points where thermocouples will be placed were determined by the thermal camera. 


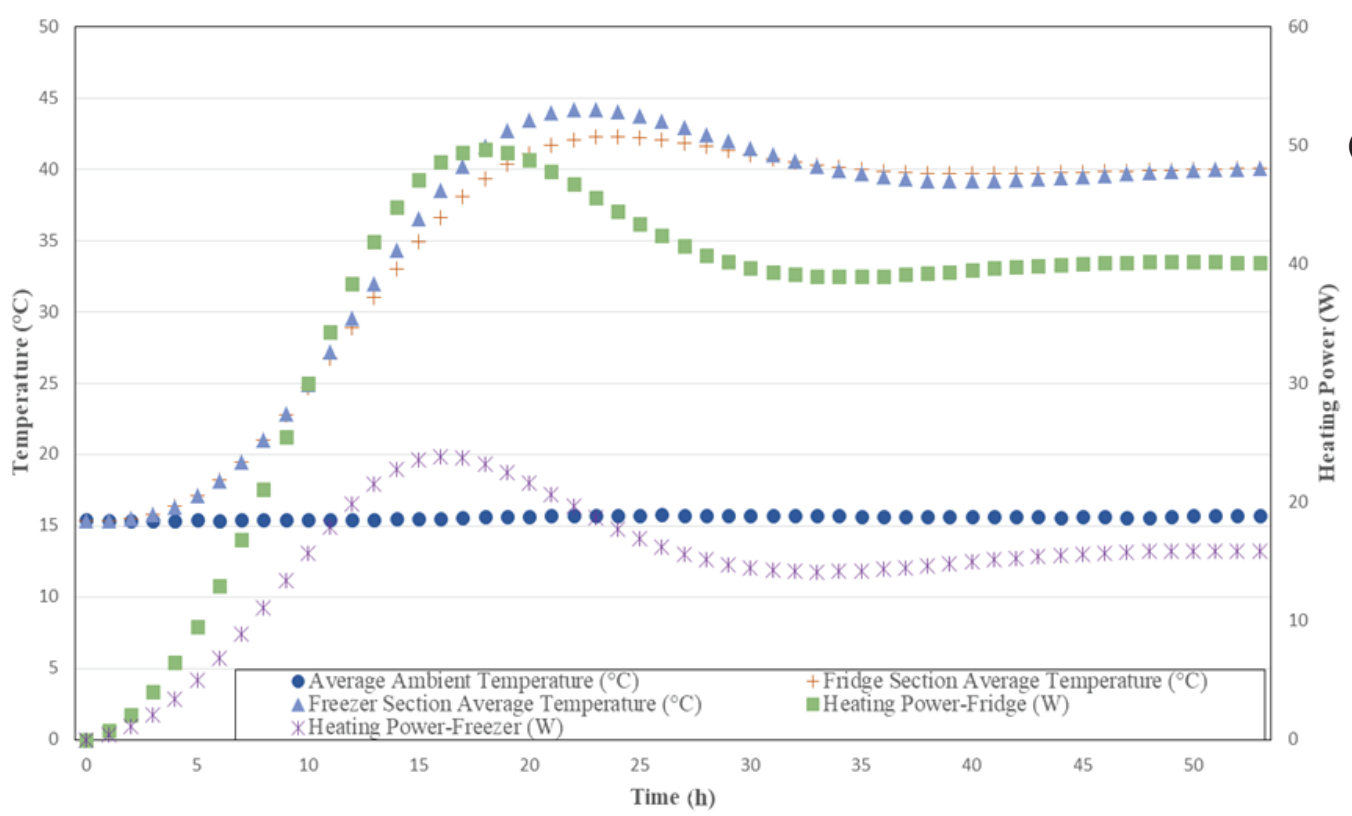

(a)

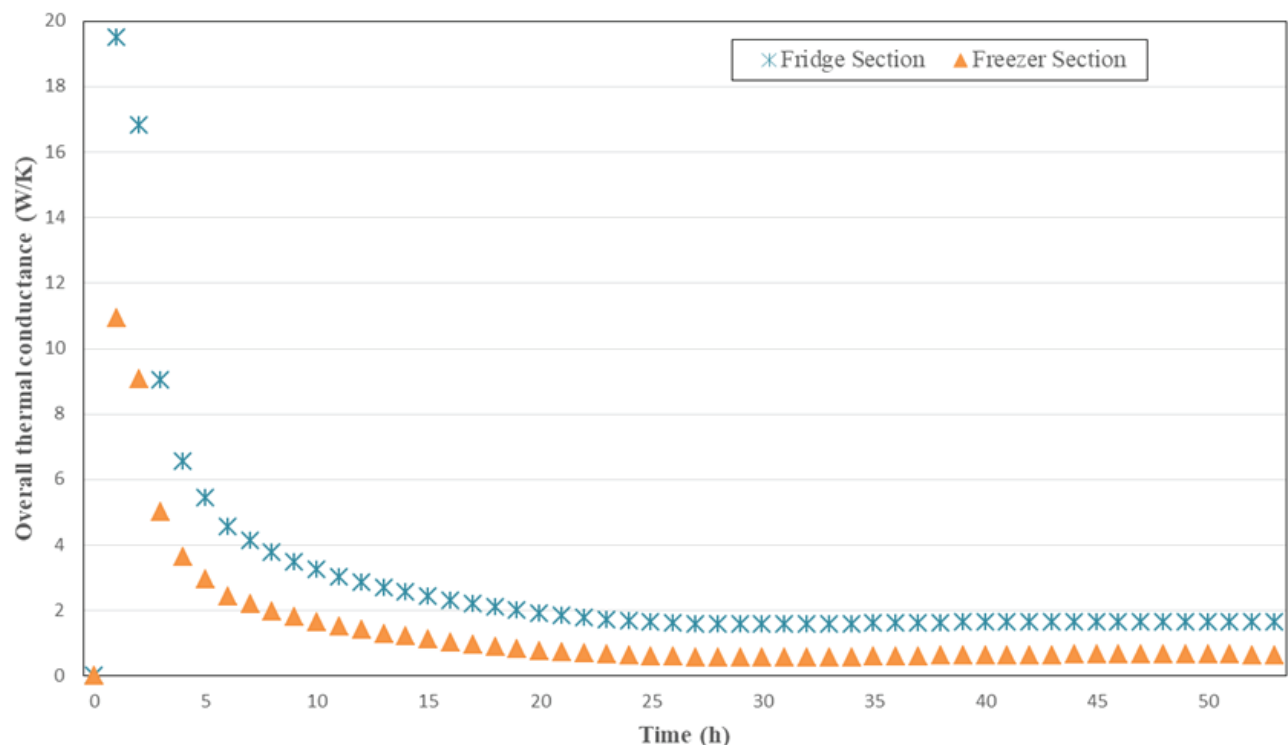

(b)

FIG. 2: Experimental results: (a) the change of temperature profiles and heating powers for sections, (b) the change of overall thermal conductance during $53 \mathrm{~h}$

\section{NUMERICAL STUDY}

\subsection{Geometry and Mesh Details}

Calculations were performed in ANSYS-FLUENT v19.0 ${ }^{\circledR}$. A two-dimensional CFD model was developed to investigate the temperature distribution in the gasket region. Since the focus of the study was to eliminate condensation on the gasket, simulations were limited to the gasket and its surroundings (Fig. 5). 


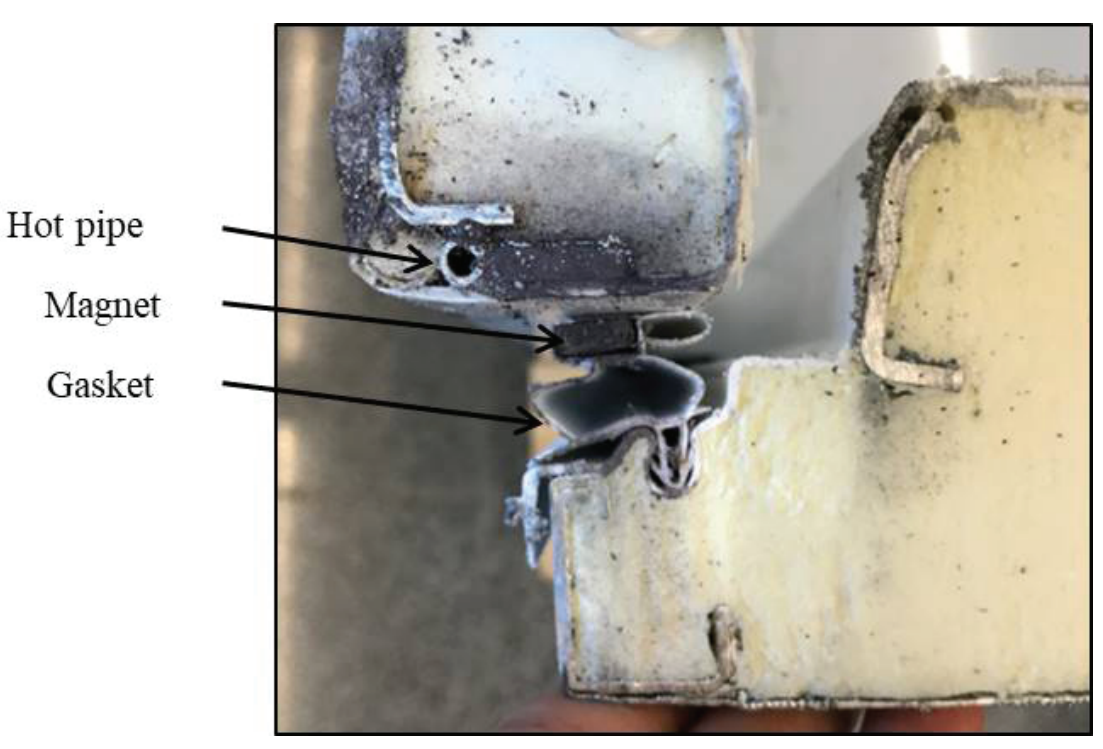

FIG. 3: Sectional view of gasket region

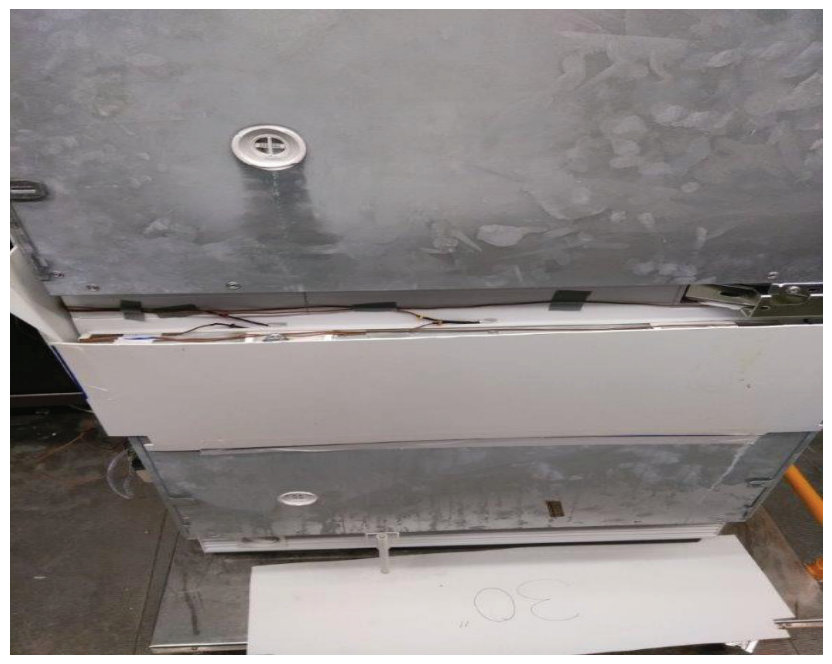

FIG. 4: Experimental setup for temperature measurements

A nonuniform structured mesh is used to discretize the computational domain. Several models with different cell numbers were tested and these models have $125,532,284,057,414,257$, and 521,700 cells, respectively. The optimal number of cells to select is 414,257 because there is no significant change in the temperature gradient after this point.

The thermal conductivities of the materials used in the analysis were listed in Table 1.

\subsection{Mathematical Model}

A two-dimensional analysis was simulated under steady-state laminar flow conditions $\left(\mathrm{Ra}<10^{9}\right)$. Also the flow has been studied as laminar in similar studies (Gupta et al., 2007; Gao et al., 2017; Yan et al., 2016; Amara et al., 2008). In addition, some studies have shown that turbulence does not change the air temperature pattern (Deschamps et al., 1999; Kingston et al., 1994). The flow inside the refrigerator compartments is assumed to be in- 


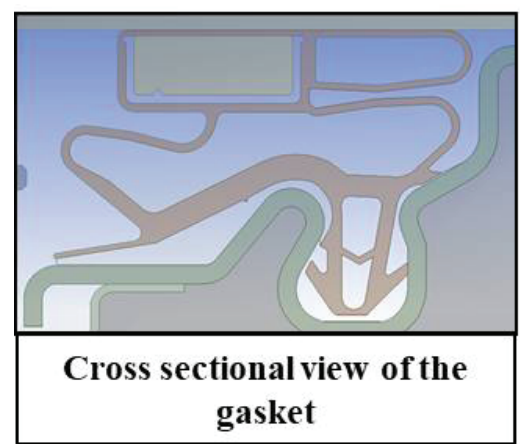

Fridge section

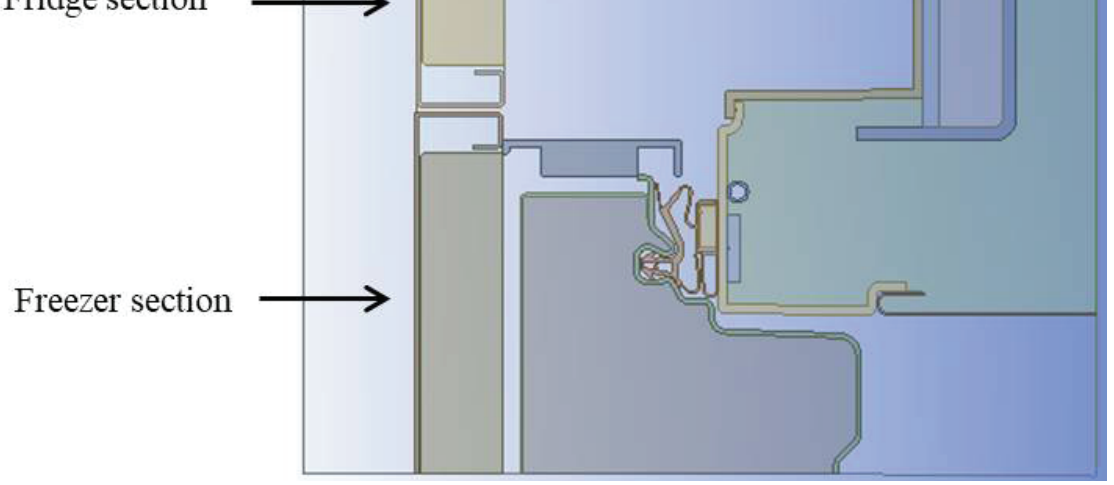

FIG. 5: Geometry of the gasket region

TABLE 1: Thermal conductivities of materials used in simulation

\begin{tabular}{|c|c|}
\hline Material & Thermal Conductivity $(\mathbf{W} / \mathbf{m} \cdot \mathbf{K})$ \\
\hline Air & 0.0242 \\
\hline Gasket & 0.15 \\
\hline Magnet & 12.39 \\
\hline Polyurethane & 0.022 \\
\hline ABS & 0.25 \\
\hline Steel & 60.5 \\
\hline
\end{tabular}

compressible because of the low Mach number. The Boussinesq approximation was used for the model. The pressure-velocity coupling is achieved by a SIMPLE algorithm. The momentum and energy conservation equations are discretized using the second-order upwind scheme. The governing equations are two-dimensional continuity equation, momentum equations, and energy equation. With the foregoing approximations, the overall continuity equation and momentum equations reduce to

$$
\begin{gathered}
\frac{\partial u}{\partial x}+\frac{\partial v}{\partial y}=0 \\
u \frac{\partial u}{\partial x}+v \frac{\partial u}{\partial y}=-\frac{1}{\rho} \frac{\partial p}{\partial x}+\vartheta\left(\frac{\partial^{2} u}{\partial x^{2}}+\frac{\partial^{2} u}{\partial y^{2}}\right)
\end{gathered}
$$




$$
u \frac{\partial v}{\partial x}+v \frac{\partial v}{\partial y}=-\frac{1}{\rho} \frac{\partial p}{\partial y}+\vartheta\left(\frac{\partial^{2} v}{\partial x^{2}}+\frac{\partial^{2} v}{\partial y^{2}}\right)+g \beta\left(T-T_{0}\right)
$$

For the temperature distribution calculations, the energy equation can be written as

$$
u \frac{\partial T}{\partial x}+v \frac{\partial T}{\partial y}=k\left(\frac{\partial^{2} T}{\partial x^{2}}+\frac{\partial^{2} T}{\partial y^{2}}\right)
$$

\subsection{Conditions}

The data obtained from the experimental study were used as boundary conditions in the simulations. These data are given in Table 2 .

\section{RESULTS AND DISCUSSION}

\subsection{Verification of the Results}

In the experiments, carried out to investigate the condensation formed on the surface of the gasket, temperature measurements were taken at four points where the gasket was in contact with the ambient air. The measured points are shown in Fig. 6.

TABLE 2: Boundary conditions

\begin{tabular}{|c|c|}
\hline Location & Temperature $\left({ }^{\mathbf{}} \mathbf{C}\right)$ \\
\hline Fridge section temperature & 4 \\
\hline Freezer section temperature & -18 \\
\hline Test room temperature & 25 \\
\hline Hot pipe temperature-Fridge & 26 \\
\hline Hot pipe temperature-Freezer & 27 \\
\hline
\end{tabular}

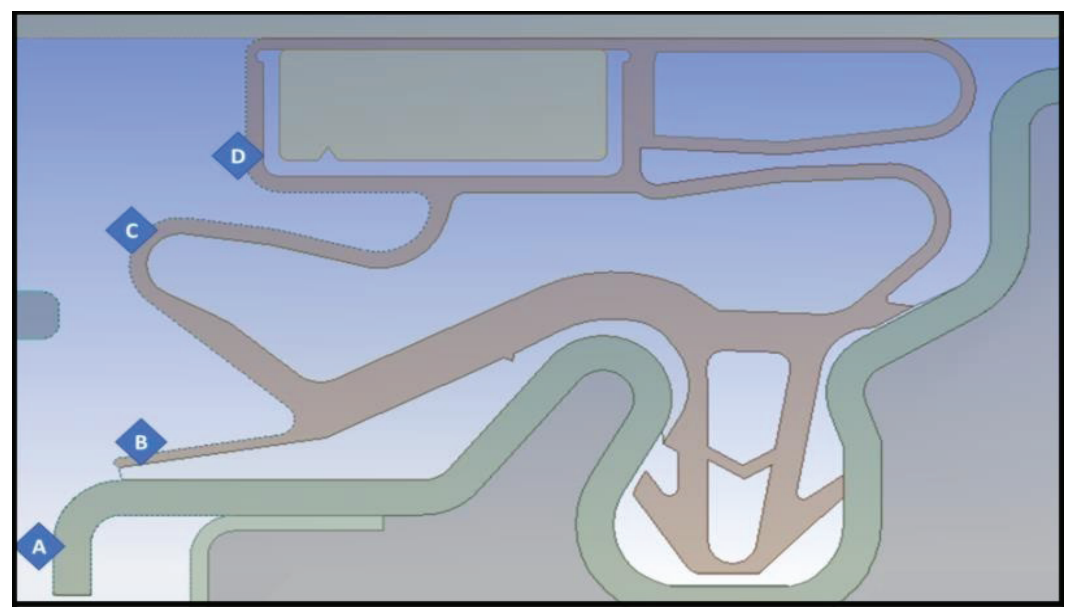

FIG. 6: Thermocouples' placements on the gasket region 
TABLE 3: Comparison of the simulation results with experiments

\begin{tabular}{|c|c|c|c|c|}
\hline Temperature $\left({ }^{\mathbf{0}} \mathbf{C}\right)$ & $\boldsymbol{T}_{\mathbf{A}}$ & $\boldsymbol{T}_{\mathbf{B}}$ & $\boldsymbol{T}_{\mathbf{C}}$ & $\boldsymbol{T}_{\mathbf{D}}$ \\
\hline Experiment & 23.85 & 23.62 & 22.65 & 23.03 \\
\hline Simulation & 24.03 & 23.38 & 22.31 & 22.80 \\
\hline $\mathrm{T}_{\text {Diff }}$ & -0.18 & 0.24 & 0.34 & 0.23 \\
\hline
\end{tabular}

Results from experiments and simulations were compared in Table 3 and, as is seen, a relatively good agreement has been achieved between simulation and experimental results.

\subsection{Development of New Gasket Design}

The air chamber is a common design in all gaskets and it is an important design parameter as it ensures a resistance to heat transfer. However, since the material connecting the air chambers will be made of gasket material and this material's heat transfer coefficient is higher than the air so heat transfer will increase. Therefore, optimum design parameters should be considered and this should be taken into consideration when adding air chambers to the design. In the conventional design there is only a big air chamber in the middle; this big chamber is divided into other small chambers in the new design. In this way, six different air chambers and several walls were created inside the gasket (Fig. 7). These design differences have a number of positive effects on temperature distribution. One of these, in the new design the transfer wall is formed to be inclined with respect to the contact wall of the gasket. This provides quick heat transfer to the target area efficiently, thus increasing the temperature of the inner
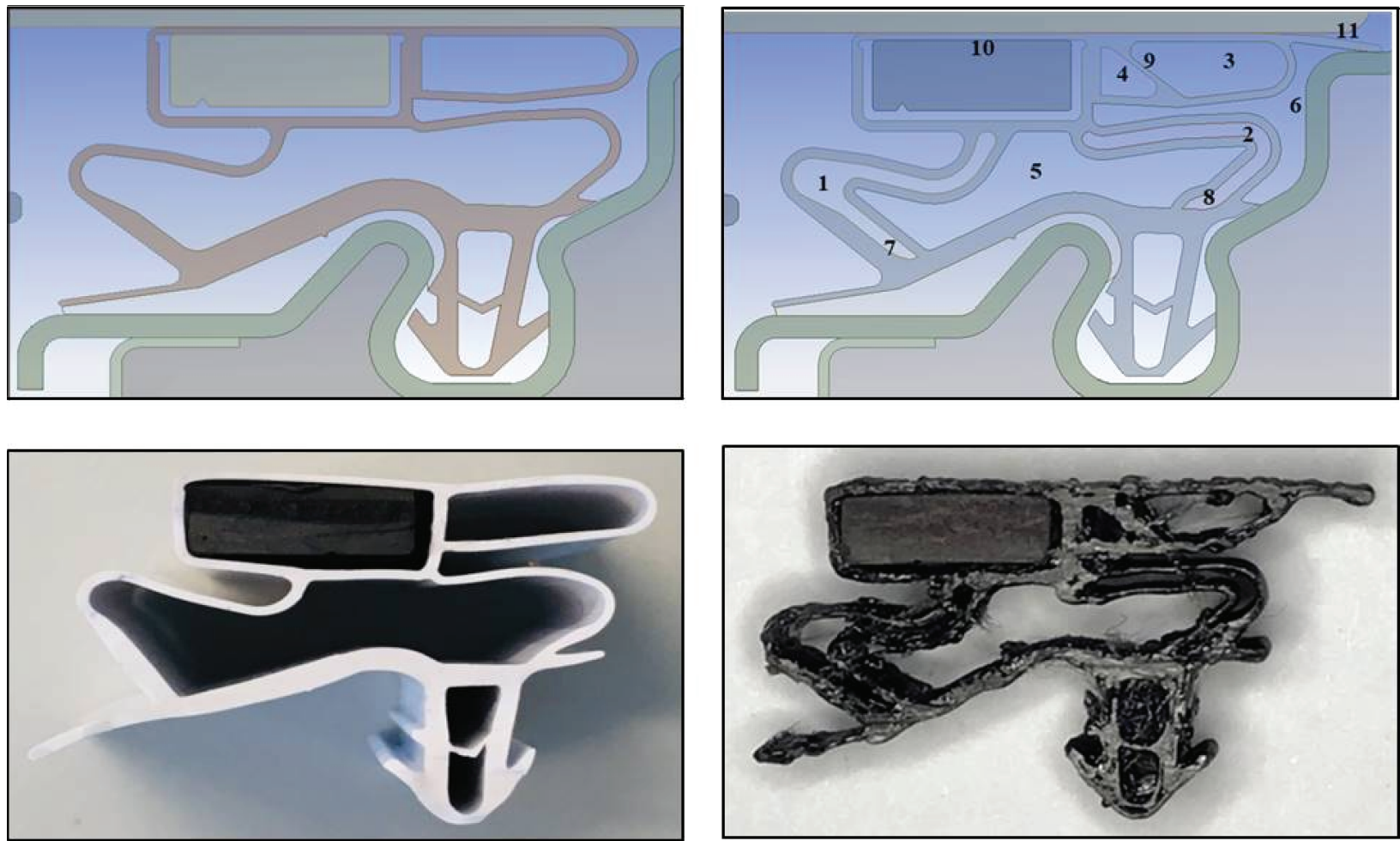

FIG. 7: Comparison of the new gasket produced in the three-dimensional printer (right) and conventional one (left): 1) first air chamber, 2) second air chamber, 3) third air chamber, 4) fourth air chamber, 5) fifth air chamber, 6) sixth air chamber, 7) first sidewall couples, 8) second sidewall couples, 9) transfer wall, 10) contact wall, 11) rib 
surface of the gasket, which is required for preventing condensate formation on the surface of the gasket. Also, the increase in the surface area of the gasket due to the form of the first and second sidewall couples ensures more interaction with the outer environment of the gasket. This results in enhanced heating of the gasket and decrease in the condensation formation on the outer surface of the gasket. And also, the new designed gasket comprises a fifth air chamber between the first sidewall couple and the second sidewall couple. Such an additional air chamber has a contribution to the decrease of the temperature difference between the inner and outer surfaces of the gasket. Thus, an improved thermal insulation is provided efficiently.

\subsection{Comparison of Temperature Fields}

The temperature fields obtained from simulations under defined boundary conditions are shown in Fig. 8. A new designed gasket comprises a transfer wall formed between the 3rd air chamber and the 4th air chamber for heat transfer from a hot pipe on the cabinet to the 6th air chamber through extension between the contact wall and the 6th air chamber (Fig. 7). By means of heat transfer to the 6th air chamber, the temperature of the inner surface of the gasket is increased, thereby rendering the temperature difference between the inner and outer surfaces of the gasket reduced relatively. Hence, the condensation problem on the outer surface of the gasket is decreased. This 6th air chamber is formed from a rib extending from the gasket towards the door face remaining inside the cabinet when the door is in closed position. The rib protruding from the 3rd air chamber avoids any extra loss of heat inwards the cabinet. The most remarkable effect in the temperature distributions seen in Fig. 8 is due to the mentioned design differences.

As is seen in Fig. 9, while one of the gasket surfaces faces the outside of the refrigerator, the other surface faces the inside of the refrigerator. Temperature distributions along the $x$ axis were investigated separately for these two sections (Figs. 10 and 11).
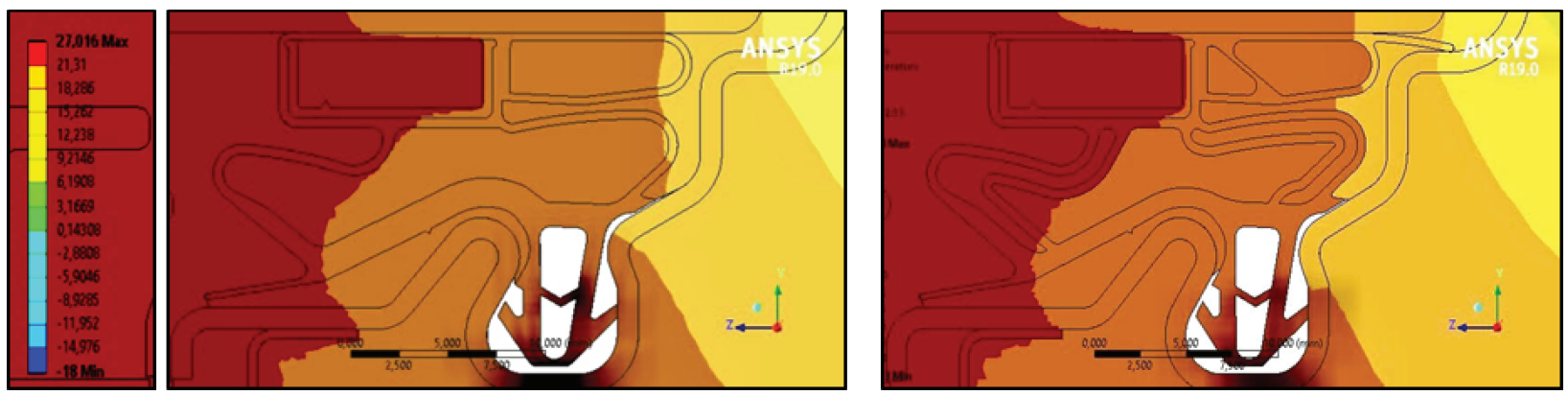

FIG. 8: Temperature distribution around the conventional gasket (a) and the new designed gasket (b)

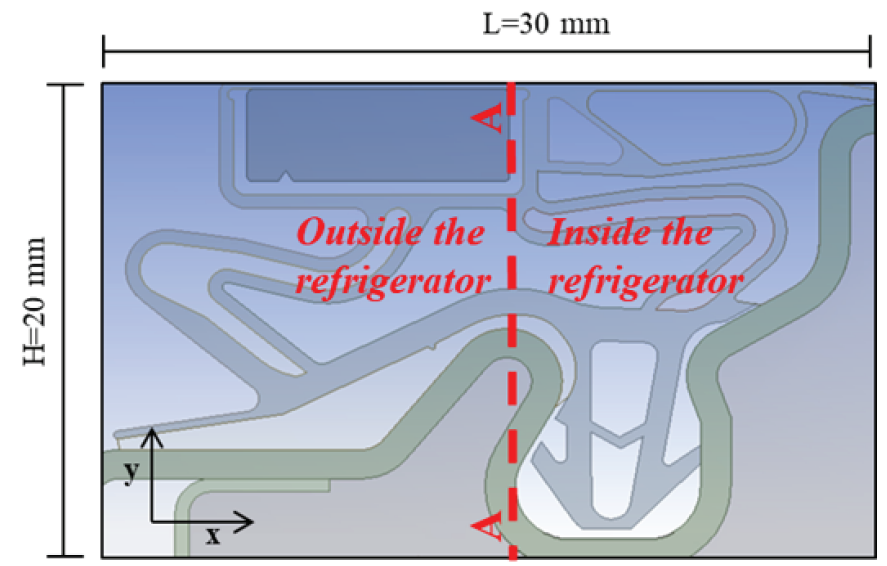

FIG. 9: Two-dimensional geometry of the gasket used in simulations 


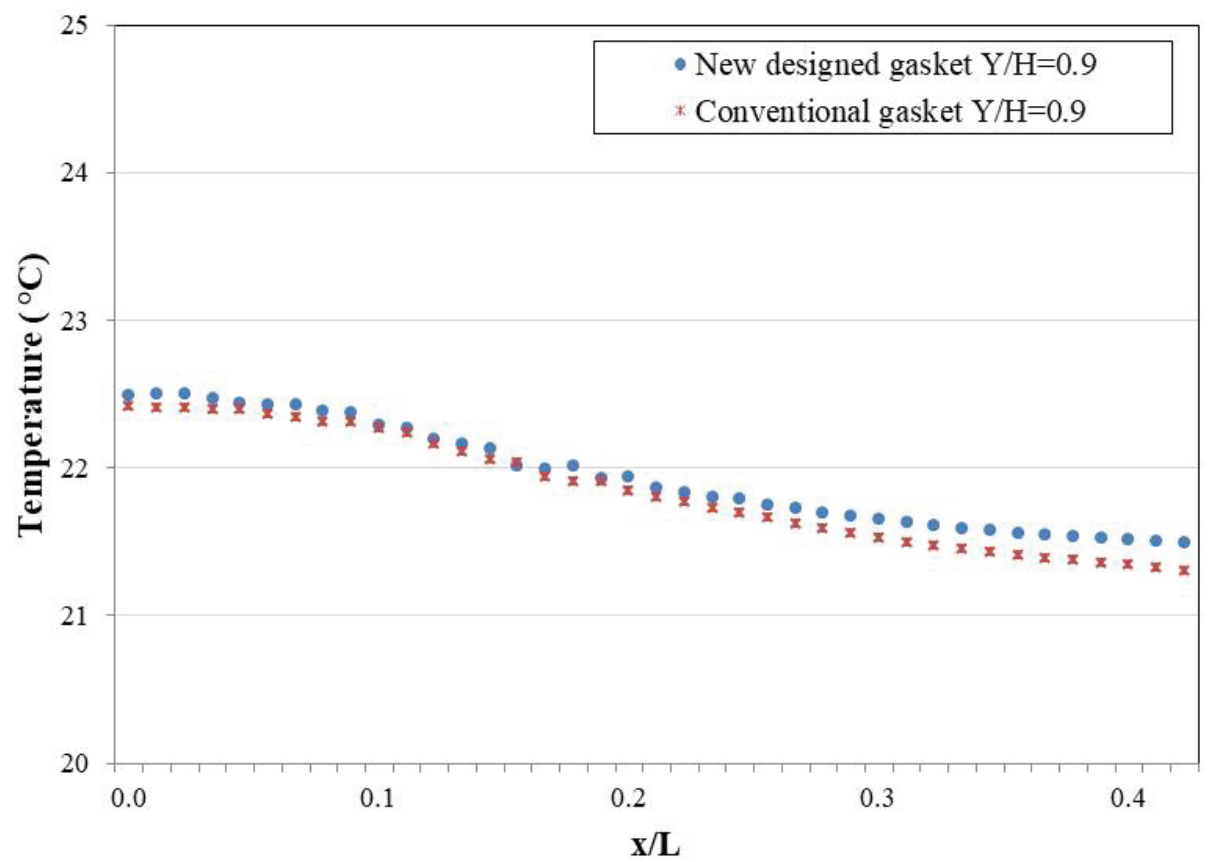

FIG. 10: Comparison of temperature distributions for the part of the gasket that is outside the refrigerator

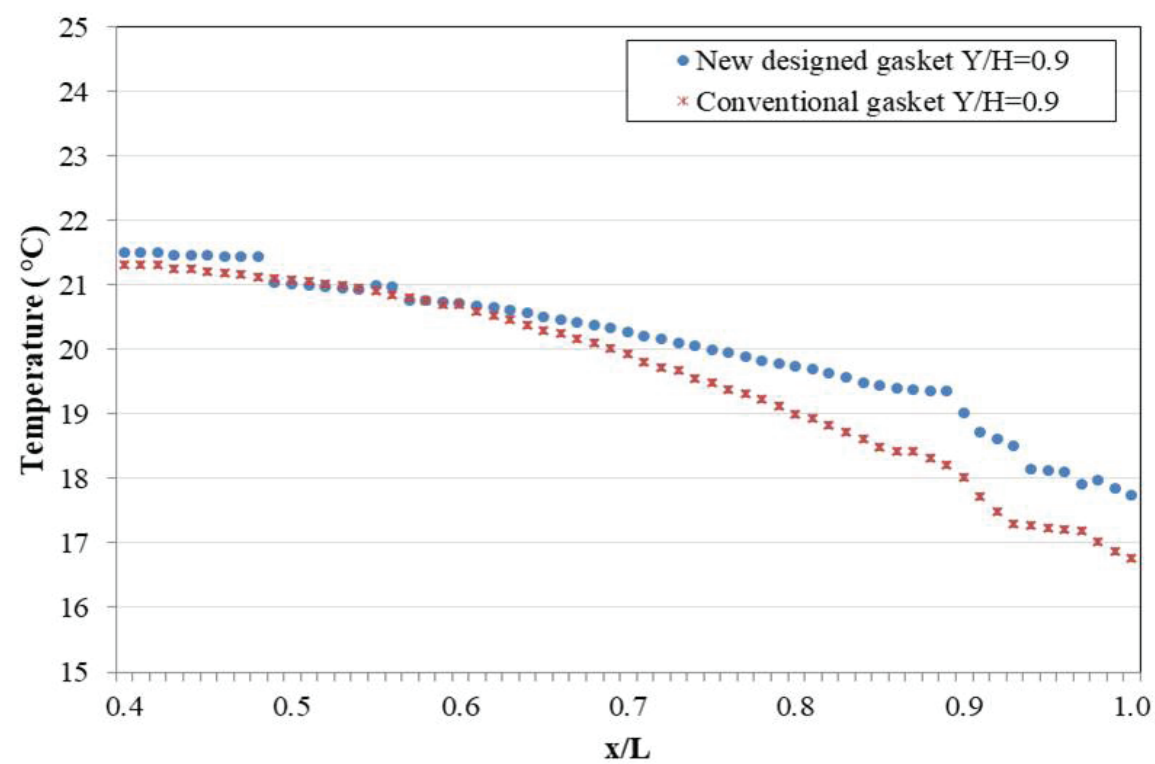

FIG. 11: Comparison of temperature distributions for the part of the gasket that is inside the refrigerator

Figure 10 shows the temperature distribution for the part of the gasket that is outside the refrigerator. As can be seen on the simulated temperature profiles, changes made in the 1st air chamber of the gasket have little effect on the temperature increase. When we examine the temperature differences of the gasket for the surface facing inside the refrigerator (Fig. 11), the temperature increase reaches approximately $1.21^{\circ} \mathrm{C}$ especially in the $2 \mathrm{nd}, 3 \mathrm{rd}$, 
and 6th air chambers. The reason for this temperature rise is the 4th air chamber created with the transfer wall and the 6 th air chamber created with said rib, these improvements in the design contribute to the heat insulation. If we examine the temperature values along the $x$ axis in this region, where the temperature increase is most prominent (between the contact wall and the 6th air chamber, $Y / H=0.9$ ), it is observed that the rate of increase in temperature values reaches up to $7 \%$ at some points (see Fig. 11).

\section{CONCLUSIONS}

Gaskets used in refrigerators reduce the heat transfer between the outer environment and the inner cabinet of the refrigerator. Although a heating pipe is used, condensation may occur on the outer surface of the gasket, especially under high temperature and humidity conditions. The problem of condensation on the gasket surface, which has not been studied much in the literature, was investigated in this study. Accordingly, the factors causing condensation formation have been investigated and a new gasket has been designed to improve the solution. The critical points of the gasket were evaluated with preliminary research and simulations developed accordingly. It was then decided to add new air chambers to the gasket design. With the new air chambers added to the gasket design, the rate of increase in temperature values on the gasket reached around $7 \%$ in the region from the transfer wall to the rib. But, for the part of the gasket that faces the outer environment, these effects have been relatively limited.

With this study, it is expected to contribute to the literature on refrigerator gasket design, which has been studied very limited in the literature. The future studies are as follows. First, in the present study, since it is known that there is condensation formation on the surface, the purpose of the study is not to determine the amount of condensation on the surface, but to prevent condensation by increasing the temperatures on the gasket as much as possible. The amount of condensation formed on the gasket surface in future research can be modeled. Second, the newly designed gasket obtained as a result of the study should be manufactured and tested to compare the results with the simulations.

\section{ACKNOWLEDGMENT}

This research was supported by the BSH Home Appliances, Turkey. The authors are gratefully thankful to the BSH Home Appliances Refrigeration Development Center, Turkey for the support.

\section{REFERENCES}

Afonso, C. and Castro, M., Air Infiltration in Domestic Refrigerators: The Influence of the Magnetic Seals Conservation, Int. J. Refrig., vol. 33, pp. 856-867, 2010.

Amara, S.B., Laguerre, O., Charrier-Mojtabi, M.C., Lartigue, B., and Flick, D., PIV Measurement of the Flow Field in a Domestic Refrigerator Model: Comparison with 3D Simulations, Int. J. Refrig., vol. 31, no. 8, pp. 1328-1340, 2008.

Bansal, P., Vineyard, E., and Abdelaziz, O., Advances in Household Appliances-A Review, Appl. Therm. Eng., vol. 31, pp. 3748-3760, 2011.

Belman-Flores, J.M., Barroso-Maldonado, J.M., Rodríguez-Muñoz, A.P., and Camacho-Vázquez, G., Enhancements in Domestic Refrigeration, Approaching a Sustainable Refrigerator-A Review, Renew. Sustain. Energy Rev., vol. 51, pp. 955-968, 2015 .

Boeng, J. and Melo, C., Mapping the Energy Consumption of Household Refrigerators by Varying the Refrigerant Charge and the Expansion Restriction, Int. J. Refrig., vol. 41, pp. 37-44, 2014.

Bolaji, B.O. and Huan, Z., Ozone Depletion and Global Warming: Case for the Use of Natural Refrigerant-A Review, Renew. Sustain. Energy Rev., vol. 18, pp. 49-54, 2013.

Bolaji, B.O., Selection of Environment-Friendly Refrigerants and the Current Alternatives in Vapor Compression Refrigeration Systems, TRGJSM J. Sci. Manage, vol. 1, pp. 22-26, 2011.

British Standards Institution, Household Refrigerating Appliances, Characteristics and Test Methods, BS EN 62552:2013, 2013.

Deschamps, C.J., Prata, A.T., Lopes, L.A.D., and Schmid, A., Heat and Fluid Flow inside a Household Refrigerator Cabinet, Proc. 20th IIR Int. Congress of Refrigeration, Sydney, 1999.

Gao, F., Naini, S.S., Wagner, J., and Miller, R., An Experimental and Numerical Study of Refrigerator Heat Leakage at the Gasket Region, Int. J. Refrig., vol. 73, pp. 99-110, 2017. 
Geppert, J. and Stamminger, R., Analysis of Effecting Factors on Domestic Refrigerators Energy Consumption in Use, Energy Convers. Manage., vol. 76, pp. 794-800, 2013.

Gulmez, M., Experimental Investigation of Heat Losses of the Refrigerator Gasket and Designing a New Gasket Section to Prevent External Condensation, Master's, Istanbul Arel University, Istanbul, 2019.

Gupta, J.K., Gopal, M.R., and Chakraborty, S., Modeling of a Domestic Frost-Free Refrigerator, Int. J. Refrig., vol. 30, no. 2, pp. 311-322, 2007.

International Electrotechnical Commission, General Requirements for the Competence of Testing and Calibration Laboratories, ISO/IEC 17025:2017, 2017.

Kingston, P., Woolley, N., and Tridimas, Y., Fluid Flow and Heat Transfer Calculations in a Domestic Refrigerator, in FIDAP UK User Meeting, Fluent France, SA, pp. 1-11, 1994.

Liu, G., Yan, G., and Yu, J., Research on Test Method of Heat Transfer Coefficient for Refrigerator Gasket, Int. J. Refrig., vol. 110, pp. 106-120, 2020.

Negrão, C.O.R. and Hermes, C.J.L., Energy and Cost Savings in Household Refrigerating Appliances: A Simulation-Based Design Approach, Appl. Energy, vol. 88, pp. 3051-3060, 2011.

Sim, J.S. and Ha, J.S., Experimental Study of Heat Transfer Characteristics for a Refrigerator by Using Reverse Heat Loss Method, Int. Commun. Heat Mass Transf., vol. 38, no. 5, pp. 572-576, 2011.

Yan, G., Chen, Q., and Sun, Z., Numerical and Experimental Study on Heat Transfer Characteristic and Thermal Load of the Freezer Gasket in Frost-Free Refrigerators, Int. J. Refrig., vol. 63, pp. 25-36, 2016. 